\title{
A rare case of hypercalcemia-induced pancreatitis in a first trimester pregnant woman
}

\author{
Carine Ghassan Richa1,2,3, Khadija Jamal Saad1,2,4, Ali Khaled Chaaban1,5,6 and Mohamad Souheil El Rawas1,2,7
}

1Rafic Hariri University Hospital, Beirut, Lebanon, 2Department of Medicine, Endocrinology Division, Lebanese University, Hadath, Lebanon, ${ }^{3}$ Endocrinology Department, Rafic Hariri University Hospital, Beirut, Lebanon, ${ }^{4}$ Endocrinology Department, Mount Lebanon Hospital, Beirut, Lebanon, ${ }^{5}$ Department of Radiology, Beirut Governmental University Hospital, Beirut, Lebanon, ${ }^{6}$ Diagnostic Radiology, Radiology Department, and ${ }^{7}$ Clinical Endocrinology, Endocrinology Department, Rafic Hariri University Hospital, Beirut, Lebanon

Correspondence should be addressed to C G Richa

Email

karine.richa69@gmail.com

\section{Summary}

The objective of the study is to report a case of acute pancreatitis secondary to hypercalcemia induced by primary hyperparathyroidism in a pregnant woman at the end of the first trimester. The case included a 32-year-old woman who was diagnosed with acute pancreatitis and severe hypercalcemia refractory to many regimens of medical therapy in the first trimester of pregnancy. She was successfully treated with parathyroidectomy in the early second trimester with complete resolution of hypercalcemia and pancreatitis. Neonatal course was unremarkable. To our best knowledge, this is a rare case when primary hyperparathyroidism and its complications are diagnosed in the first trimester of pregnancy. In conclusion, primary hyperparathyroidism is a rare life-threatening condition to the fetus and mother especially when associated with complications such as pancreatitis. Early therapeutic intervention is important to reduce the morbidity and mortality. Parathyroidectomy performed in the second trimester can be the only solution.

\section{Learning points:}

- Learning how to make diagnosis of primary hyperparathyroidism in a woman during the first trimester of pregnancy.

- Understanding the complications of hypercalcemia and be aware of the high mortality and sequelae in both fetus and mother.

- Providing the adequate treatment in such complicated cases with coordinated care between endocrinologists and obstetricians to ensure optimal outcomes.

\section{Background}

Many reports describe the association between primary hyperparathyroidism and pancreatitis (3); however, others (7) showed that the rate of acute pancreatitis was not increased in patients with primary hyperparathyroidism. In pregnancy, few cases of primary hyperparathyroidism complicated by pancreatitis and preeclampsia have been reported mainly in the third trimester and in the postpartum period (Table 1). Herein, we present the case of a 32-year-old pregnant woman presenting with an acute pancreatitis secondary to a parathyroid adenoma at the end of the first trimester, with total remission after parathyroidectomy. 
Table 1 Cases of hyperparathyroidism and pancreatitis in pregnancy.

\begin{tabular}{|c|c|c|c|c|c|c|c|}
\hline Authors & PMH & GA & $\begin{array}{l}\text { Presenting signs and } \\
\text { symptoms }\end{array}$ & $\mathrm{Ca}$ & $\begin{array}{l}\text { Maternal } \\
\text { outcomes }\end{array}$ & Fetal outcomes & Surgery \\
\hline $\begin{array}{l}\text { Hong } \\
\text { et al. (1) }\end{array}$ & $\begin{array}{l}\text { Nephrolithiasis } \\
3 \text { consecutives } \\
\text { miscarriages } \\
\text { in the } \\
\text { previous } \\
4 \text { years IVF } \\
\text { performed }\end{array}$ & $30+4$ weeks & $\begin{array}{l}\text { Severe epigastric } \\
\text { pain, vomiting, } \\
\text { fever, tachypnea, } \\
\text { tachycardia, } \\
\text { elevated blood } \\
\text { pressure }\end{array}$ & $17.9^{a}$ & ARF intubation & $\begin{array}{l}\text { C-section } \\
31 \text { weeks }+3 \text { days MV } \\
\text { for } 2 \text { days transient } \\
\text { hypocalcemia }\end{array}$ & Day 6 PP \\
\hline $\begin{array}{l}\text { Kryslak } \\
\text { et al. (2) }\end{array}$ & $\begin{array}{l}\text { Reccurent } \\
\text { miscarriages } \\
\text { due to } \\
\text { pancreatitis }\end{array}$ & 8th week & $\begin{array}{l}\text { Abdominal pain, } \\
\text { nausea, vomiting, } \\
\text { anorexia }\end{array}$ & $10.4^{a}$ & $\begin{array}{l}\text { Hypercalcemia } \\
\left(12.8^{\mathrm{a}}\right) \\
\text { nephrolithiasis } \\
\text { hypotension }\end{array}$ & $\begin{array}{l}\text { SVD } 38 \text { weeks } \\
\text { hypercalcemia }\left(11.6^{a}\right)\end{array}$ & $\begin{array}{l}\text { Not done } \\
\text { medical } \\
\text { therapy: } \\
\text { calcitonin }\end{array}$ \\
\hline $\begin{array}{l}\text { Lee } \\
\text { et al. (3) }\end{array}$ & $\begin{array}{l}1 \text { spontaneous } \\
\text { abortion }\end{array}$ & PP & $\begin{array}{l}\text { Acute abdominal } \\
\text { pain }\end{array}$ & $11.5^{a}$ & $\begin{array}{l}\text { IA abcess due to } \\
\text { pancreatitis } \\
\text { hydronephrosis } \\
\text { due to } \\
\text { nephrolithiasis } \\
\text { neurologic } \\
\text { complications }\end{array}$ & Healthy baby 37 weeks & $\begin{array}{l}11 \text { weeks } \\
\text { PP }\end{array}$ \\
\hline $\begin{array}{l}\text { Liu } \\
\text { et al. (4) }\end{array}$ & Irrelevant & 31 weeks & $\begin{array}{l}\text { Nausea, vomiting, } \\
\text { irritability, high } \\
\text { blood pressure }\end{array}$ & $15.16^{a}$ & $\begin{array}{l}\text { Preeclampsia } \\
\text { hypercalcemic } \\
\text { crisis }\left(13.12^{a}\right) \\
\text { pancreatitis PP }\end{array}$ & $\begin{array}{l}\text { C-section } 31 \text { weeks } \\
\text { hypercalcemia } \\
(12.56 \mathrm{a})\end{array}$ & PP \\
\hline $\begin{array}{l}\text { Dale } \\
\text { et al. (5) }\end{array}$ & Irrelevant & 32 weeks & $\begin{array}{l}\text { High blood } \\
\text { pressure, } \\
\text { scotomata } \\
\text { epigastric pain }\end{array}$ & $9.9^{a}$ & $\begin{array}{l}\text { Preeclampsia } \\
\text { hypercalcemia } \\
\left(10.2^{\mathrm{a}}\right)\end{array}$ & C-section 32 weeks & PP \\
\hline $\begin{array}{l}\text { Burks } \\
\text { et al. (6) }\end{array}$ & Irrelevant & 11 weeks & $\begin{array}{l}\text { Refractory nausea } \\
\text { vomiting }\end{array}$ & $12.6^{a}$ & $\begin{array}{l}\text { Worsening } \\
\text { symptoms } \\
\text { hypercalcemia } \\
(14.1 \text { a) }\end{array}$ & Healthy baby & $\begin{array}{l}12 \text { weeks } \\
\text { of } \\
\text { gestation }\end{array}$ \\
\hline $\begin{array}{l}\text { Present } \\
\text { case }\end{array}$ & $\begin{array}{l}4 \text { years } \\
\text { infertility IVF } \\
\text { performed }\end{array}$ & 11 weeks & $\begin{array}{l}\text { Epigastric pain, } \\
\text { nausea, vomiting }\end{array}$ & $12.35^{a}$ & $\begin{array}{l}\text { Refractory } \\
\text { hypercalcemia } \\
(12.74 \text { a) }\end{array}$ & $\begin{array}{l}\text { C-section } 36 \text { weeks } \\
\text { healthy baby }\end{array}$ & $\begin{array}{l}13 \text { weeks } \\
\text { of } \\
\text { gestation }\end{array}$ \\
\hline
\end{tabular}

aTotal serum calcium in mg/dL (normal value: 8.5-10.5).

ARF, acute respiratory failure; Ca, calcium level; C-section, cesarean section; GA, gestational age; IA, intra-abdominal; MV, mechanical ventilation; PMH, past medical history; PP, postpartum; SVG, spontaneous vaginal delivery.

\section{Case presentation}

A 32-year-old lady, Gravida 1 Para 0, who underwent in vitro fertilization (IVF) because of unexplained infertility, presented at her 11th week of gestation for epigastric pain, nausea and bilious vomiting. She noted recurrent hospitalization for the same complaints even prior to her pregnancy. Past medical history was significant for chronic pruritic rash and nephrolithiasis, which has never been investigated.

\section{Investigation}

Laboratory tests showed leukocytosis with a left shift $(14900 / \mu \mathrm{L}$ with $80 \%$ neutrophils), alanine aminotransferase of 116 (normal range: 7-56 IU/L), aspartate aminotransferase of 60 (normal range: 5-40IU/L), alkaline phosphatase of $140 \mathrm{IU} / \mathrm{L}$ (normal range: 44-147 IU/L), gamma-glutamyl transpeptidase of 62 (normal range: 9-48 IU/L), direct bilirubin of 0.48 (normal range $<0.3 \mathrm{mg} / \mathrm{dL}$ ), total bilirubin of 0.74 (normal range: $0.1-1.2 \mathrm{mg} / \mathrm{dL}$ ) and elevated amylase and lipase: four to five times the upper limits of normal, 340 and $820 \mathrm{IU} / \mathrm{L}$ respectively (normal range for amylase: 10-120 IU/L and normal range for lipase: 13-60 IU/L).

Pancreatitis was diagnosed based on the clinical presentation and the laboratory findings. The patient was kept null per os (NPO) for few days, with pain control medications (meperidine $50 \mathrm{mg}$ intravenous three times per day), intravenous fluids and total parenteral nutrition (oliclinomel N4 1L per daily) at a later stage in order to maintain the caloric needs necessary for fetal growth. Lipase levels decreased to $600 \mathrm{IU} / \mathrm{L}$ after $48 \mathrm{~h}$, then to $491 \mathrm{IU} / \mathrm{L}$ after $72 \mathrm{~h}$.

While investigating the etiology of pancreatitis, an ultrasound of her abdomen showed biliary sludge with 
no signs of cholecystitis and an endoscopic ultrasound confirmed the absence of common bile duct dilatation. However, her calcium level was found to be significantly elevated with a value of $12.35 \mathrm{mg} / \mathrm{dL}$ (normal range: $8.5-10.2 \mathrm{mg} / \mathrm{dL}$ ) with a low serum phosphorus and magnesium levels, $2.03 \mathrm{mg} / \mathrm{dL}$ and $1.35 \mathrm{mg} / \mathrm{dL}$ respectively (normal phosphorus range: $2.5-4.5 \mathrm{mg} / \mathrm{dL}$ and normal magnesium range: $1.7-2.2 \mathrm{mg} / \mathrm{dL}$ ). A 24 -h urine calcium collection showed markedly elevated levels, $380 \mathrm{mg} /$ day (normal range from 100 to $300 \mathrm{mg} /$ day) with a urine volume of $4700 \mathrm{~mL} / 24 \mathrm{~h}$ and urine creatinine of $658 \mathrm{mg}$ (normal range: $600-2000 \mathrm{mg} / 24 \mathrm{~h}$ ). Parathyroid hormone (PTH) level was elevated, $301.8 \mathrm{pg} / \mathrm{mL}$ (normal range: $10-65 \mathrm{pg} / \mathrm{mL}$ ) with a low 25-hydroxyvitamin D level of $4.2 \mathrm{ng} / \mathrm{mL}$ (normal range: $20-50 \mathrm{ng} / \mathrm{mL}$ ). Based on the above mentioned results, primary hyperparathyroidism was identified and resulting hypercalcemia was thought to be the culprit behind this patient's pancreatitis.

A neck ultrasound revealed no parathyroid lesions. A subsequent magnetic resonance imaging (MRI) of the neck was preferred over a sestamibi scan view the fetal radiation exposure risk associated with the latter. Neck MRI revealed a $2.8 \times 1.7 \times 1 \mathrm{~cm}$ oval-shaped homogenous high intensity lesion, just inferior to the right thyroid lobe consistent with a parathyroid adenoma (Figs 1, 2 and 3). Thus, a multidisciplinary decision involving the gynecology, endocrinology and surgery teams was undergone and the patient was advised to have a parathyroidectomy in her early second trimester, which is considered the safest period for surgery during pregnancy.

\section{Treatment}

At the same time, the initial target to reduce the patient's serum calcium level failed despite various attempts using aggressive saline infusion (up to $4 \mathrm{~L}$ per day), furosemide (60 mg intravenous daily), calcitonin $4 \mathrm{IU} / \mathrm{kg}$ twice daily, later increased to $8 \mathrm{IU} / \mathrm{kg}$ three times daily. Moreover, and despite its potential adverse effects in pregnancy, zoledronic acid was administered at a dose of $4 \mathrm{mg}$ intravenously after discussing its risks and benefits with the patient and view the refractory hypercalcemia, but calcium level remained elevated (Figure 4).

So, an uneventful minimally invasive parathyroidectomy was performed after 14 days of diagnosis, with a subsequent significant intraoperative drop in PTH (from 1332 to $150 \mathrm{pg} / \mathrm{mL}$ ) indicating adequate adenoma removal. Pathology confirmed the presence of a $2.8 \times 1.6 \times 1 \mathrm{~cm}$ right inferior parathyroid adenoma.

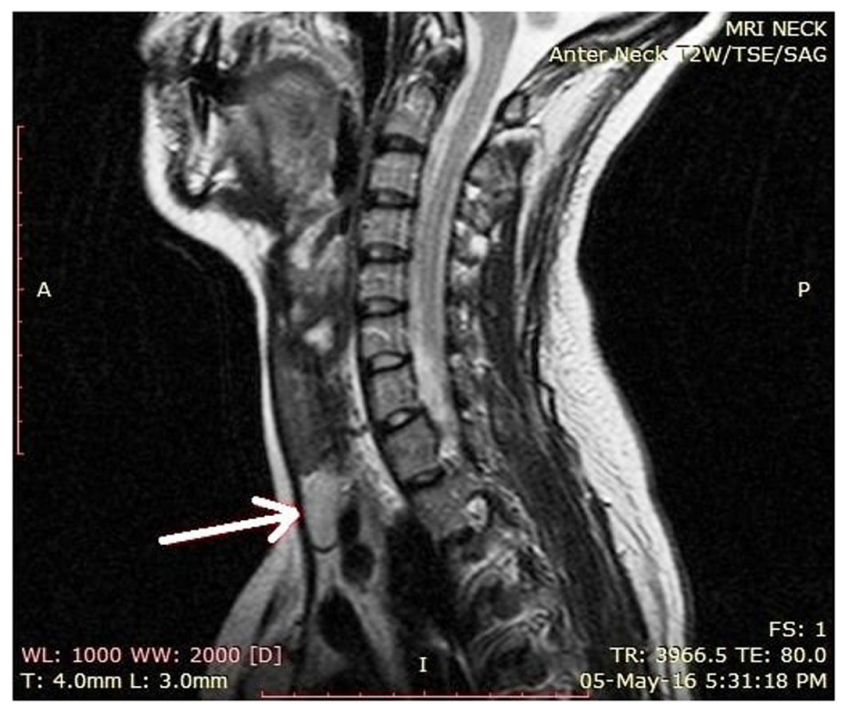

Figure 1

Brain magnetic resonance imaging of anterior neck. T2-weighted imaging sagittal view with the arrow showing the parathyroid adenoma.

\section{Outcome and follow-up}

The patient experienced a rapid resolution of her acute pancreatitis with improvement in her abdominal pain and pruritic rash. On postoperative day 3 , the calcium level dropped to $8.45 \mathrm{mg} / \mathrm{dL}$, phosphorus level to $1.2 \mathrm{mg} /$ $\mathrm{dL}$ and magnesium level to $1.41 \mathrm{mg} / \mathrm{dL}$ suggesting hungry bone syndrome. Simultaneously, the patient started

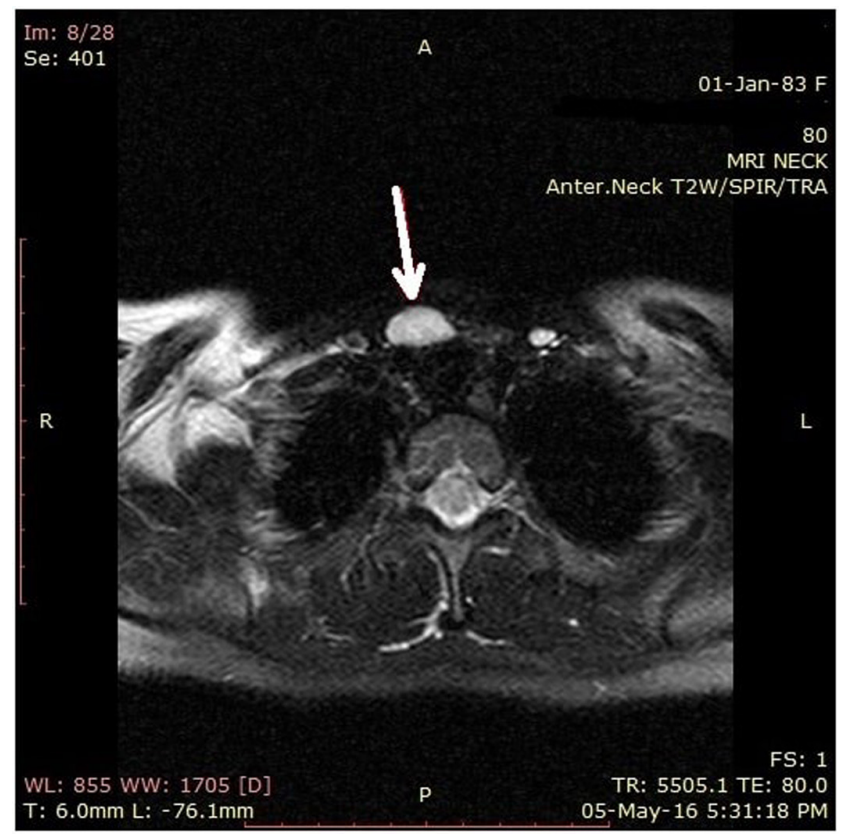

Figure 2

Brain magnetic resonance imaging of anterior neck. T2-weighted imaging axial view with the arrow showing the parathyroid adenoma. 


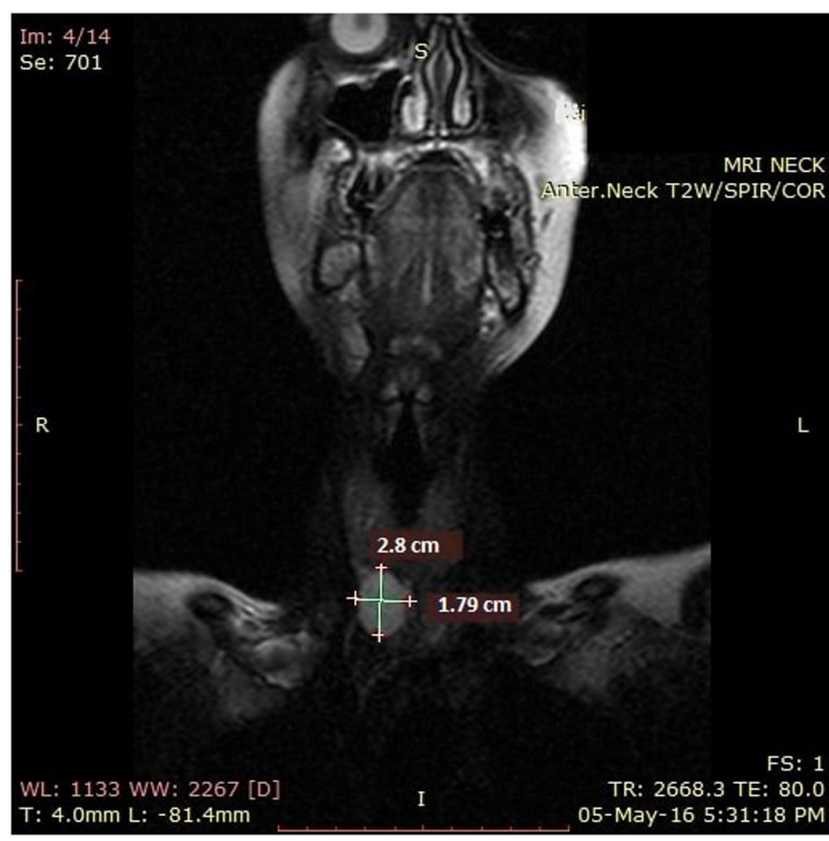

Figure 3

Brain magnetic resonance imaging of anterior neck. T2-weighted imaging coronal view demonstrating an oval shape mass inferior to the right lobe of the thyroid consistent with an enlarged right inferior parathyroid adenoma.

complaining of perioral and upper extremity numbness that resolved after $2 \mathrm{~g}$ of intravenous calcium gluconate. Thereafter, calcium $600 \mathrm{mg}$ twice daily and calcitriol $1 \mu \mathrm{g}$ daily were started. The patient was successfully discharged home on day 4 post parathyroidectomy and a one-week follow-up noted the absence of symptoms with a calcium level of $9.2 \mathrm{mg} / \mathrm{dL}$ and phosphorus level of $3.8 \mathrm{mg} /$ dL. Calcium and calcitriol replacement were therefore discontinued.

The patient was closely monitored and after around 6 months (at 36 weeks of gestation), she had an uneventful delivery.

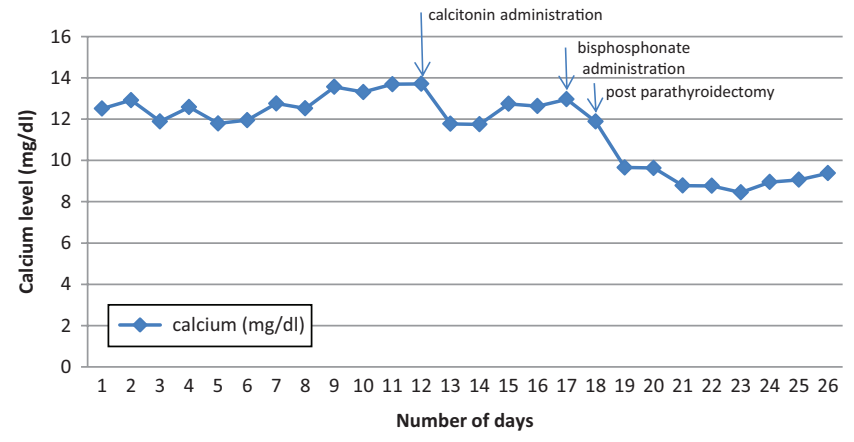

Figure 4

Variation of calcium level pre and post parathyroidectomy.

\section{Discussion}

Primary hyperparathyroidism causing hypercalcemia, while uncommon during pregnancy, is concerning and requires special care for mother and fetus to prevent problems such as nephrolithiasis, pancreatitis or hypercalcemic crisis and more importantly, major fetal complications such as hypocalcemia and tetany, preterm delivery and fetal demise even when pregnancy and delivery are uneventful $(5,8)$. Diagnosis is challenging, as symptoms may mimic other features observed frequently in pregnancy. Timely diagnosis and early intervention are crucial in this condition.

Primary hyperparathyroidism (PHPT) during pregnancy is thought to occur in less than $1 \%$ of cases. However, many authors agree that the actual number of cases in pregnancy is underestimated especially that gestational hyperparathyroidism (HPT) remains undiagnosed in a significant number of patients and is often suggested after numerous unexplained miscarriages (9). Despite its rarity, PHPT is the third most common endocrine disease in pregnancy (10) with up to 200 cases reported in the literature (11). Primary adenoma is the most common etiology of PHPT. The majority of patients (23-80\%) are asymptomatic (8).

The diagnosis of primary hyperparathyroidism is very challenging due to the non-specificity of symptoms, the clinical similarities to other obstetrical diseases including hyperemesis gravidarum, the decrease in total calcium levels secondary to gestational hemodilution, increase in glomerular filtration rate leading to hypercalciuria and hypoalbuminemia, transplacental transfer of calcium and elevated estrogen levels in pregnancy (8). Moreover, clinicians have limited radiological options in pregnant women view the risk of fetal radiation which limits the use of sestamibi scan (5). Alternative imaging modalities have been suggested including the ${ }^{99 m}$ Tc-MIBI scan (12) and the cervical ultrasound (11).

Decreased fertility in pregnant women with hyperparathyroidism is controversial. Primary hyperparathyroidism can lead to higher rates of fetal complications. The most serious outcomes include neonatal tetany secondary to hypocalcemia and suppression of the fetal parathyroid glands, still birth and respiratory failure in newborns $(5,8)$.

On the other hand, obstetrical complications of PHPT are usually uncommon because calcium levels are only mildly elevated in the majority of cases. However, significant calcium elevations can lead to pancreatitis. Hypercalcemic crisis can occur in the postpartum period because of the decreased shunting of calcium to fetus (8). 
Norman et al. reported a higher incidence of miscarriages (3.5-fold) in pregnant women with PHPT who did not undergo parathyroidectomy, whereas Abood and Vestergaard, and Hirsh and coworkers found no difference in the outcomes (10).

Abood and Vestergaard also reported no increase in abortion rate and no need for parathyroidectomy but increased risk of delivery by cesarean section in mild PHPT-associated pregnancy. Weight and length birth, and Apgar score are usually not affected in mild PHPT (13). Miscarriages occur most commonly between week 10 and 15 , in patients with calcium levels exceeding $11.4 \mathrm{mg} /$ $\mathrm{dL}$ and with history of previous miscarriages (9). Women diagnosed with hyperparathyroidism during pregnancy can report one or more miscarriages that can go unnoticed if calcium levels are not alarming.

Acute pancreatitis in pregnancy is also rare with an incidence ranging between 0.02 and $0.1 \%$ (5).

Gallstone is the most common cause in pregnancy, due to weight and hormonal effects. A second scenario in pregnancy is hypertriglyceride-induced pancreatitis due to high fat levels, increased estrogen and familial tendency (14).

Acute pancreatitis, as well as gallstone disease, occurs more frequently in the third trimester with advanced gestational age (15).

In addition, primary hyperparathyroidism is rarely a cause of acute or chronic pancreatitis with a prevalence of $3.6 \%(7)$.

The frequency of acute pancreatitis is much higher in pregnant women with hyperparathyroidism (7-13\%) than in non-pregnant ones. It is assumed that it is more common in primiparas and mainly in the first and third trimester (2).

In small subset of patients, primary hyperparathyroidism can be attributed to radiation exposure or to rare genetic abnormalities, mainly MEN1, MEN-2, familial parathyroid hyperplasia syndromes or jaw-tumor syndrome, especially in young population. Somatic loss of one MEN1 allele results in altered menin protein, which is a tumor suppressor, leading to the formation of adenoma involving one or more parathyroid glands. CDC73 mutations result in decreased parafibromin protein activity, which also acts as a tumor suppressor, leading to the development of adenoma or rarely carcinoma. Cyclin D1 overexpression is seen in adenoma and parathyroid hyperplasia. CaSR and other mutations have also been identified (16). Thus, genetic disease may have consequences on surgical therapy.

Management of PHPT in pregnancy is individualized according to symptoms, severity of hypercalcemia and gestational age (8). Early recognition and management reduce the complications, especially when diagnosis is established early in pregnancy. Mild hypercalcemia in pregnancy can be safely monitored, as compared to moderate and severe hypercalcemia (12).

Management is similar in pregnant and non-pregnant patients and consists on initial aggressive saline infusion. If needed, many medications can be used. Calcitonin, a category B drug, lowers calcium by inhibiting osteoclast formation. It is a relatively weak agent that rapidly lowers calcium concentration by a maximum of $1-2 \mathrm{mg} / \mathrm{dL}$ with an onset of action of 4-6h. Its major adverse effect is tachyphylaxis. The efficacy of calcitonin is limited to the first $48 \mathrm{~h}$ of diagnosis even with repeated doses. Calcitonin does not cross the placenta and has been safely used in pregnancy. However animal studies showed that high doses of calcitonin may induce low birth weight in offsprings (2).

Furosemide, category $\mathrm{C}$ medication, is mainly used to promote calciuresis.

Cinacalcet activates calcium-sensing receptors (CaSR) on parathyroid cells, C-cells of the thyroid, and renal distal tubular cells, thus reduces PTH, increases calcitonin release and decreases renal calcium reabsorption. However, its efficacy on the mother and fetus are still lacking. This drug is considered category C. CaSR are present in the placenta; therefore, cinacalcet inhibits active placental calcium transport. Multiple studies suggested adverse effects secondary to its use. Cinacalcet suppresses fetal PTH and can induce neonatal hypocalcemia (12).

Bisphosphonates, considered category $\mathrm{C}$ drugs, act by decreasing bone resorption. Their optimal benefit is reached 2-4 days after administration; therefore, they should be given in combination with calcitonin. They are the most potent drug category, but their use should be limited to emergent cases when their benefits outweigh their risks, to patients requiring short-term therapy and to those with severe hypercalcemia prior to surgery (17). Bisphosphonates are known to affect fetal bone development.

Oral phosphates, labeled as pregnancy category C medication, promote urinary calcium excretion but carry a risk of soft tissue calcifications and diarrhea.

In addition, management of severe hypercalcemia may require hemodialysis and in refractory cases, parathyroidectomy (8).

In pregnant patients, special attention is given to the potential complications of treatment and its adverse effects on women and fetuses. Thus, surgical approach remains the safest therapeutic option, preferably performed before pregnancy. During pregnancy, parathyroidectomy is recommended in the second trimester when anesthesia and 
surgical techniques are relatively safe and fetal organogenesis is complete (9). Anesthesia during parathyroidectomy in the first and third trimesters may lead to spontaneous abortion and premature delivery respectively (11).

Our patient is a good example; sheimproved dramatically after parathyroidectomy with total amelioration of her abdominal pain, rash, pancreatitis and hypercalcemia.

A major consideration after successful parathyroidectomy is hungry bone syndrome. The incidence of this syndrome during pregnancy is still unknown. Large size of parathyroid adenomas, high preoperative levels of blood urea nitrogen and alkaline phosphatase and old age are important risk factors for the development of hungry bone syndrome.

\section{Conclusion}

Primary hyperparathyroidism is a rare devastating event during pregnancy. Diagnosis can be challenging, and complications may be life threatening. A well-organized multidisciplinary approach is recommended to prevent adverse outcomes in woman and fetus.

\section{Declaration of interest}

The authors declare that there is no conflict of interest that could be perceived as prejudicing the impartiality of the research reported.

\section{Funding}

This research did not receive any specific grant from any funding agency in the public, commercial or not-for-profit sector.

\section{Patient consent}

Written informed consent has been obtained from the patient for publication of the submitted article and accompanying images.

\section{Author contribution statement}

Dr Carine Ghassan Richa:wrote this article; Dr Mohamad Souheil EL Rawas : patient's physician,, revised critically this manuscript and gave final approval of the version; Dr Khadija Jamal Saad: participated in drafting this manuscript; Dr Ali Khaled Chaaban: contributed to diagnostic imaging.

\section{References}

1 Hong MK, Hsieh CT, Chen BH, Tu ST \& Chou PH. Primary hyperparathyroidism and acute pancreatitis during the third trimester of pregnancy. Journal of Maternal-fetal Medicine 200110 214-218. (https://doi.org/10.1080/jmf.10.3.214.218)

2 Krysiak R, Wilk M \& Okopien B. Recurrent pancreatitis induced by hyperparathyroidism in pregnancy. Archives of Gynecology and Obstetrics 2011284 531-534. (https://doi.org/10.1007/s00404-0101668-x)

3 Lee CC, Chao AS, Chang YL, Peng HH, Wang TH \& Chao A. Acute pancreatitis secondary to primary hyperparathyroidism in a postpartum patient: a case report and literature review. Taiwanese Journal of Obstetrics and Gynecology 201453 252-255. (https://doi. org/10.1016/j.tjog.2013.01.029)

4 Liu Y, Wang J-N, Huang Y, Zhu Y-H, Liu R-L, Xu C-F \& Li X. Acute pancreatitis and preeclampsia induced by parathyroid sdenoma in pregnancy: a case report and literature review. International Journal of Clinical and Experimental Medicine $2016922652-22655$.

5 Dale A, Holbrook BD, Sobel L \& Rappaport VJ. Hyperparathyroidism in pregnancy leading to pancreatitis and preeclampsia with severe features. Case Reports in Obstetrics and Gynecology 20172017 1-3. (https://doi.org/10.1155/2017/6061313)

6 Burks M, Harary S, Solorzano CC \& Bao S. Primary hyperparathyroidism in a first-trimester woman with hyperemesis gravidarum and pancreatitis. AACE Clinical Case Reports 20173 e31-e34. (https://doi.org/10.4158/EP151136.CR)

7 Khoo T, Vege SS, Abu-Lebdeh HS, Ryu E, Nadeem S \& Wermers RA. Acute pancreatitis in primary hyperparathyroidism: a populationbased study. Journal of Clinical Endocrinology and Metabolism 200994 2115-2118. (https://doi.org/10.1210/jc.2008-1965)

8 Malekar-Raikar S \& Sinnott BP. Primary hyperparathyroidism in pregnancy - a rare cause of life-threatening hypercalcemia: case report and literature review. Case Reports in Endocrinology 20112011 1-6. (http://dx.doi.org/10.1155/2011/520516)

9 Norman J, Politz D \& Politz L. Hyperparathyroidism during pregnancy and the effect of rising calcium on pregnancy loss: a call for earlier intervention. Clinical Endocrinology 200971 104-109. (https://doi.org/10.1111/j.1365-2265.2008.03495.x)

10 Hirsch D, Kopel V, Nadler V, Levy S, Toledano Y \& Tsvetov G. Pregnancy outcomes in women with primary hyperparathyroidism. Journal of Clinical Endocrinology and Metabolism 2015100 2115-2122. (https://doi.org/10.1210/jc.2015-1110)

11 Rchachi M, et al. Primary hyperparathyroidism in pregnancy - a review. Annals of African Medicine 201716 145-147. (https://doi. org/10.4103/aam.aam_61_16)

12 Rubin M \& Silverberg SJ. Use of cinacalcet and 99mTc-sestamibi imaging during pregnancy. Journal of the Endocrine Society 20179 1156-1159. (https://doi.org/10.1210/js.2017-00308)

13 Aboud A \& Vestergaard P. Pregnancy outcomes in women with primary hyperparathyroidism. European Journal of Endocrinology 2014 171 69-76. (https://doi.org/10.1530/EJE-13-0966)

14 Pitchumoni C \& Yegneswaran B. Acute pancreatitis in pregnancy. World Journal of Gastroenterology 200915 5641-5646. (https://doi. org/10.3748/wjg.15.5641)

15 Abdullah B, Kathiresan Pillai T, Huay Cheen L \& Joshua Ryan R. Case report severe acute pancreatitis in pregnancy. Case Reports in Obstetrics and Gynecology 20152015 1-4. (httpa://doi. org/10.1155/2015/239068)

16 Familial isolated hyperparathyroidism. Genetics Home Reference 2018 $1-6$.

17 Gokkaya N, Gungor A, Bilen A, Bilen H, Gviniashvili D \& Karadeniz Y. Primary hyperparathyroidism in pregnancy: a case series and literature review. Gynecological Endocrinology 201632 783-786. (https://doi.org/10.1080/09513590.2016.1188916) 